\title{
The Applied Neurobiology of Human Spinal Cord Injury: A Review
}

\author{
A. Kakulas, AO, MD(Hon Athens), MD(WA), FRACP, FRCPath \\ Department of Neuropathology, Royal Perth Hospital and Neuromuscular Re- \\ search Institute, University of Western Australia, Perth, Western Australia
}

\section{Summary}

The immediate reward of neuropathology is to provide the paraplegist with an explanation for the patient's neurological symptoms. This information also assists clinical management by defining the pathology of the bony spine, cord and systemic complications. A detailed knowledge of human spinal cord injury neuropathology also sets the context for basic research. The information on which these studies are based is derived from 191 acute coroner's cases, 95 survivors of spinal cord injury collected since 1958 with the assistance of Sir George Bedbrook, 108 'medical' disorders, 37 others with metastatic carcinoma and 129 normal subjects, giving a total of 560 cases.

In the hyperacute material and in many who survived the injury, an important observation is the finding of continuity of CNS tissue at the level of the lesion. Of 67 patients who were 'clinically' complete, 50 showed some continuity across the injured segments. This anatomical finding encourages the work of restorative neurologists as it provides a basis for enhancement or modification of residual functions.

In work currently supported by the Medical Research Foundation of Western Australia, a data bank of clinicopathological information has been established. This allows detailed correlations which may assist clinical management and restorative interventions. In addition the Foundation supports the anatomical investigation of the distribution and vulnerability of particular nerve fibre tracts.

Nerve root regeneration is a common finding in patients who have survived their injury for more than a few months. It appears that such fibres undergo continuous reorientation in a vertical direction. With the identification of Schwann cell growth factors and their role in CNS regeneration nerve roots extending into the cord deserve close scrutiny.

A complete knowledge of the developmental neurobiology of the CNS is a necessary prelude to possible future successful transplantation and regeneration. Plasticity, reflexology, information concerning growth and inhibitory factors, receptors, peptides, endocrines and neurotransmitters are integral to the problem. Genes which control growth and differentiation are now being identified and this work gives hope that basic research may lead to replacement of lost CNS tissues in the long term. 
Key words: Neuropathology of spinal injuries; Clinical neurobiology; Future directions.

Conventional neuropathology contributes to the clinical management of spinal cord injury (SCI) through its accurate description of the lesions. Thus a knowledge of the exact nature of the disorder in descriptive and temporal terms defines the problem of SCI and assists in the planning of management and of therapeutic interventions. The dynamic neuropathology also provides an essential framework for basic research which may be directed toward the development of an 'effective' treatment for SCI in the future.

Within the evolution of the SCI lesions, the primary initiating factors need to be carefully delineated from secondary causes of damage. The effects of pure mechanical injury need to be distinguished from those changes which result from anoxia or impaired perfusion of blood compounded by shock or respiratory problems in an unconscious patient. This approach focuses attention on those factors which determine the tissue injury and which may be amenable to future modification or correction.

It is a truism that a full knowledge of the molecular pathobiology of human SCI is required before any reconstructive interventions, be they physical, physiological, pharmacological or biological, may be successfully introduced. Therefore when the exact molecular circumstances of embryological and fetal growth and development are known there is a possibility that suitable conditions may be re-established for the functional repair of adult SCI in the future. In the broadest molecular terms, it is evident that growth and regeneration genes are switched off in the mature CNS in higher vertebrates as a result of internal regulating processes and/or the influence of external trophic factors. For instance it is known that the presence of Schwann cells will allow central axonal regeneration to occur (Aguayo et al., 1982a, 1982b). Needless to say, all relevant trophic factors need to be idenified and the ideal embryological conditions reconstituted in order to reconstruct new spinal cord tissues. Research in this field is rapidly advancing and a brief review of progress follows.

In our age of recombinant DNA technology the problem can be expressed as follows. 'The cure for SCI is a matter of derepressing the genes responsible for multiplication of neuroblasts, the sprouting of neurites and the regrowth of axons and collaterals with the restoration of physiological connections and functionally useful reflexes by means of guided plasticity and synaptogenesis'.

In the light of recent advances it is not too early to begin to consider how successful reconstruction of the lost segments of the cord may be undertaken. Even today modification, augmentation and other physiological changes may be induced in spinal patients (Dimitrijevic, 1988). However, one must be careful not to raise false hopes among the spinally injured. On the other hand it is also necessary to be bold enough to outline the prerequisites for 'curative' neurological research. With the advent of recombinant DNA technology a revolution has begun where the very processes of life itself may be influenced and manipulated. In medicine this revolution does not only apply to the inherited genetic diseases but has equal application to acquired disorders such as SCI. A brief 
review of the clinical neuropathology and the more applicable recent discoveries in molecular neurobiology now follow.

\section{Neuropathology and experimental neurobiology of SCI}

\section{Clinical neuropathology}

Some basic neuropathological correlations have been achieved but there is much more to be gained in this respect (Bedbrook and Kakulas, 1968; Kakulas and Bedbrook, 1969, 1976). In the initial period it is known that spinal shock is responsible for flaccid paralysis which is found initially in most patients. This is the spinal equivalent to cerebral concussion. It is also known that in the following days or weeks neurological recovery is possible to a surprising extent. This improvement phase is usually complete in 3-6 weeks. The neurobiological mechanisms which underlie such early recovery are not understood. Theoretical possibilities are: recovery from spinal concussion by restoration of synaptic connections; the restoration of molecular integrity of myelin and axonal conductance; the subsidence of edema; and restoration of capillary perfusion with phagocytosis of extravasated red blood cells.

The indications for surgical intervention in the acute phase are few, if any. In most cases the dimension of the spinal canal is restored spontaneously resuming its original size. From neuropathological studies it is known that traumatic hematomyelias or large subarachnoid, subdural and extradural hematomas of sufficient size to compress the cord and impede blood flow are rare. Although bone fragments may be present from a 'burst' fracture they rarely compress the injured cord. On the other hand the autonomic disturbances including hypotension, respiratory insufficiency, systemic shock and anoxia render surgical intervention hazardous. Because many membranes and subcellular organelles are near the point of breakdown, even the slightest further interference may cause potentially reversible cellular perturbations to become permanent.

The human spinal cord contains more than 20 million very delicate nerve fibres many of which are unmyelinated and relatively unsupported by stroma. Hence this CNS tissue is extremely vulnerable to injury. From our neuropathological observations it is known that in many patients there are a large number of axons which survive the initial injury and which remain in continuity following SCI but are in an extremely parlous state.

The precarious blood supply of the spinal cord, dependent as it is on collateral segmental reinforcement, is an additional hazard. A large number of axonal fibres exist that have been temporarily compromised with loss of function but when blood flow returns, bringing oxygen and removing the 'toxic products' of tissue injury, they may recover. The possible detrimental effects of exposure of the cord, the spinal instability resulting from laminectomy, the negative pharmacological effects of sedatives, analgesics and anaesthetics and the possibility of further blood loss must all be considered when surgical intervention is being contemplated.

Other clinical neurobiological aspects pertain to the later stages. Many patients with SCI experience changes in the subjective awareness of their lower limbs and suffer phantom distortions of body image, pain, burning sensations 
and other paresthetic phenomena which can be very distressing and interfere with rehabilitation. The morphological correlates of these effects are unknown.

In a few SCI patients there is limited late neurological recovery occurring for reasons which are presently unknown. Whether such late recovery is purely neurophysiological or has a structural basis is a matter of conjecture. Unfortunately in many other SCI patients late complications may develop. The neurological level may rise due to the development of a post traumatic syringomyelia, the growth of nerve roots to the point of becoming a space occupying traumatic neuroma and the progression of degenerative arthritis causing spinal stenosis wih or without vascular insufficiency related to atheroma of the aorta and its segmental branches.

There is a need for quantitative information and some work is in progress. For instance, whether the large myelinated fibres at the periphery of the spinal cord are more vulnerable to spinal necrosis as is the case in the experimental animal (Blight and Decrescito, 1986), or whether the propriospinal pathways (the short intersegmental systems) are altered in chronic SCI. Regenerated nerve root fibres are presumed to arise from both anterior horn cells and posterior root ganglia but this has not been fully demonstrated anatomically. Whether such fibres reach the cuneate and gracile nuclei is also conjectural. It is possible that trophic factors supplied by Schwann cells in the nerve roots contribute to CNS regeneration.

\section{Experimental neurobiology}

Trauma. The following are representative of the accumulated reports of experimental SCI in animals and are provided here only as an introduction to the subject.

Blight et al. (1983a) have investigated the cellular morphology of chronic SCI in the cat especially the myelinated axons. They introduced a new method of line sampling for quantification of the lesions and showed that the larger and more peripherally placed myelinated fibres were more vulnerable to injury. Blight (1983b, 1985) also investigated the physiology of SCI in the cat using intracellular electrodes and described delayed demyelination due to macrophage invasion as a secondary phenomenon of cell damage in experimental SCI (Blight, 1985). Morphometry in experimental SCI in the cat measuring the relation of injury intensity to survival of myelinated axons was also reported (Blight and Decrescito, 1986). They found the subpial zones to be relatively spared with the larger fibres prone to demyelination. Midha et al. (1987) have investigated the effect of SCI by counting corticospinal and rubrospinal neurons. For further information the reader is referred to the publications of Balentine (1978), Das (1983), Reier (1985), Wallace et al. (1987), Young (1984), Young and Flamm (1982), Young et al. (1981, 1982).

Exploratory treatments. In general it can be said that many treatments have been tried in the attempt to minimise the effect of SCI and that all of these have been disappointing. Many are based on experimental observations in animals. Some concern the vascular reactions which take place following SCI and others relate to oedema and oxygen supply.

Glucocorticoid mechanisms in acute spinal cord injury were investigated with 
a review of the therapeutic rationale by Hall and Braughler (1982). Other treatments include the effect of oxygen therapy (Jones and Unsworth, 1978; Higgins et al., 1981) and similar work has been undertaken by Yeo (1976) who is a strong advocate of hyperbaric oxygen therapy, his concepts being based on his experimental work in sheep. More recent studies are those of Anderson (1985) who was able to experimentally dissociate hemorrhagic necrosis and loss of axonal conduction. Wallace and Tator report that naloxone fails to improve spinal cord blood flow and cardiac output after SCI, nor does it enhance clinical recovery after experimental injury (Wallace and Tator, 1986a, 1986b). The effect of calcium blockers has also been assessed with some encouraging results on blood flow (Guha et al., 1987).

\section{Regeneration and transplantation}

In the field of transplantation the works of Aguayo et al. (1982a, 1982b, 1984), Cotman et al. (1985), Cotman and Nieto-Sampedro (1985), Raisman and Ebner (1985), Lund et al. (1986) and Perez-Polo (1987) are the more prominent. Many other excellent reviews on this topic exist and the reader is referred to the literature for details (Kao, 1974; Reier, 1985).

Briefly, Aguayo (1982a, 1982b, 1984) has shown that CNS axonal regeneration is possible within grafts of peripheral nerve, thus demonstrating the positive effect of Schwann cells. Cotman and Nieto-Sampedro (1985) are involved in the evaluation of growth factors and have pioneered many of the techniques now used in experimental CNS transplantation. Inter alia they have shown that crude preparation of trophic factors enhances the survival of grafted neurons. Perez-Polo (1987) is concerned with the role of trophic CNS factors in tissue culture, showing that several such factors are beneficial.

Axonal regeneration in the spinal cord injury has been reviewed by Borgens et al. (1986). They also have shown that dorsal column axons in the guinea pig spinal cord will regenerate in the presence of an electric field applied following transection. The work of Foerster (1982) on spontaneous regeneration of cut axons in adult brain is noteworthy for its completeness. He showed that a small proportion of such axons survive the initial injury.

Mechanical factors such as relaxation and immobilisation in healing of the spinal cord have been investigated experimentally by Breig et al. (1982). Das (1983) reported his own studies and reviewed the literature on neural transplantation in the spinal cord of rats with reference to the conditions of survival, cytology and connectivity of the transplants. Further studies of the ultrastructural pathology of nerve fibres in calcium-induced myelopathy were reported by Balentine and Greene (1984). Historically, early work on the regeneration of the spinal cord post injury even prior to that of Cajal (1928) whose general conclusions were negative, was undertaken by Marinesco and Minea (1906) who reviewed the literature to that time including the work of Brown-Séquard who believed that he had obtained almost complete regeneration of the spinal cord of pigeons following transection. Marinesco and Minea (1906) compared their experimental findings in dogs with 2 human SCI patients and commented upon the lack of central nerve fibre regeneration compared with the nerve roots. 
Of particular interest in experimental neurobiology is the recent progress achieved in identifying in trophic factors an era which began with the discovery of nerve growth factor (NGF) by Levi-Montalcini in 1968 (Levi-Montalcini et al., 1975) and pursued by many others. As a result many growth or trophic factors have now been shown to influence the nervous system in addition to NGF. Schwann cell factor, fibroblast and epidermal growth factors and GAP 43 among others, are reported to have biological activity (Aguayo et al., 1982a, 1982b, 1984). For instance, Kligman and Marschak (1985) have characterised a neurite extension factor from bovine brain. Epidermal growth factor has been found in the CNS and is active in stimulating the growth of neuroblasts in vitro (Fallon et al., 1984; Gallon et al., 1984). It is also known that glia afford a unique substrate enhancing the in vitro growth of CNS neurons (Noble et al., 1984).

Nieto-Sampedro and Cotman (1985) have reviewed growth factor induction and temporal order in CNS repair. They have also found that survival of brain transplants is enhanced by extracts of injured brain (Nieto-Sampedro et al., 1984; Nieto-Sampedro et al., 1985).

Whittemore, Nieto-Sampdero et al. (1985) reviewed the stimulant neuronotrophonic factors induced by injury in neonatal, adult and aged rat brains, on mammalian brain neurons and further pursued a number of these in their ongoing studies.

Certain excitatory amino acids serve as neurotransmitters in the CNS. However, they may also produce neurotoxicity. This system is being investigated by Raigorodsky and Urca (1987).

Lenn (1987) investigated the plasticity and responses of the immature nervous system to injury showing that synapse remodelling occurred and formed a good model for analysis of the controlling mechanism. Sotelo and Alvarado-Mallart (1987) have investigated the reconstruction of the defective cerebellar circuitry in adult Purkinje cell degeneration mutant mice by Purkinje cell replacement through transplantation of solid embryonic implants. Fawcett et al. (1987) investigated the relationships between axonal regeneration and various glia including oligodendrocytes and astrocytes.

Haynes et al. (1984) provide evidence for neurotrophic regulation by betaendorphin in immature muscle. Fibroblast growth factor has been identified in the developing CNS of embryonic rats by Logan et al. (1985).

\section{Discussion and conclusions}

Advances in the discovery of trophic factors as definitive organic compounds proceed hand in hand with work on transplantation and regeneration. This work promises to provide information which may eventually be applied to the benefit of patients with SCI. Theoretical considerations in this respect were recently discussed (Kakulas, 1987). In summary these concepts are as follows. Hypothetically, if it were possible to restore growth and multiplication of nerve cells and their fibres and create new primary connections using autografts (converted to primitive neuroblasts), amenable to 're-education' through the property of plasticity then the stage would be reached to seriously consider it possible to 'cure spinal paralysis'. Work along these lines is being conducted by Raisman (1987) and his team at the National Institute for Medical Research in London; 
as recounted by Peter Banyard, editor and research director of the International Spinal Research Trust. He is said to speak of sending genes into the damaged area which have been especially prepared so that they can infiltrate the appropriate cells. Following this the reconstruction of the complex array of connections needed for the functioning nervous system is the next step. The principle being pursued is the combination of growth genes isolated from cell clones derived from the patient with other genes capable of assuring entry to specific cells in spinal tissue. In this way an encouraging beginning to the problem is underway as described in a simplified manner in the International Spinal Research Trust newsletter of December 1987. There is room, therefore, for guarded optimism with regard to the successful outcome of the neurobiological approach to spinal cord injury. The framework having being set by precise studies of the neuropathology of SCI, it is now timely for clinical neurophysiologists to develop methods for augmenting or modifying residual functions for the benefit of the patient and for the developmental neurobiologists applying the latest techniques of molecular neurobiology in seeking methods of restoration and reconstruction. Thus the first part of this report was devoted to a review of existing neuropathological knowledge followed by a consideration of the theoretical requirements for repair of lost CNS tissues in SCI in the context of current neurobiological research. Nevertheless the difficulty of the problems to be encountered should not be trivialised and it would be misleading to belive that a cure for SCI is likely to be found in the foreseeable future. However it is quite evident that work in this direction has begun in earnest.

\section{References}

Aguayo AJ, BJoRklund A, Stenevi U, et al. 1984 Fetal mesencephalic neurons survive and extend long axons across peripheral nervous system grafts inserted into the adult rat striatum. Neuroscience Letters 45:53-58.

Aguayo AJ, David S, Richardson P, et al. 1982a Axonal elongation in peripheral and central nervous system transplants. In: Federoff S, Hertz L (eds) Advances in Cellular Neurobiology, Vol 3. Academic Press, New York, pp. 215-234.

Aguayo AJ, Richardson PM, David S, et al. 1982b Transplantation of neurons and sheath cells - a tool for the study of regeneration. In: Nicholls JG (ed) Repair and Regeneration of the Nervous System. Dahlem Konferenzen, Springer-Verlag, New York, pp. 91-105.

ANDERSON TE 1985 Spinal cord contusion injury: experimental dissociation of haemorrhagic necrosis and subacute loss of axonal conduction. Fournal of Neurosurgery 62:115-119.

Balentine JD 1978 Pathology of experimental spinal cord trauma. I. The necrotic lesion as a function of vascular injury. Laboratory Investigation 39:236-253.

BALENTINE JD, GREENE WD 1984 Ultrastructural pathology of nerve fibers in calcium-induced myelopathy. Fournal of Neuropathology and Experimental Neurology 43(5):500-510.

BeDBRooK GM, KaKUlas BA 1968 Pathological findings with clinical correlation in 57 patients with spinal cord injury. Proceedings of the 4th Pan Pacific Rehabilitation Conference, pp. 248-290.

BLIGHT AR 1983a Cellular morphology of chronic spinal cord injury in the cat: analysis of myelinated axons by line-sampling. Neuroscience 10(2):521-543.

BLIGHT AR 1983b Axonal physiology of chronic spinal cord injury in the cat: intracellular recording in vitro. Neuroscience 10(4):1471-1486.

BLIGHT AR 1985 Delayed demyelination and macrophage invasion: a candidate for secondary cell damage in spinal cord injury. Central Nervous System Trauma 2(4):299-315.

BLIGHT AR, DeCRESCITO V 1986 Morphometric analysis of experimental spinal cord injury in the cat: the relation of injury intensity to survival of myelinated axons. Neuroscience 19(1):321341 .

Borgens RB, Blight AR, MuRPhy DJ 1986 Axonal regeneration in spinal cord injury: A perspective and new technique. Fournal of Comparative Neurology 250:157-167. 
Borgens RB, Blight AR, Murphy DJ, et al. 1986 Transected dorsal column axons within the guinea pig spinal cord regenerate in the presence of an applied electric field. Fournal of Commparative Neurology 250:168-180.

BREIG A, RENARD M, SteFanko S, et al. 1982 Healing of the severed spinal cord by biomechanical relaxation and surgical immobilization. Anatomica Clinica 4:167-181.

Cajal Ramon Y 1928 Degeneration and Regeneration of the Nervous System. University Press, Oxford.

Cotman CW, Nieto-Sampedro M, Whittemore SR 1985 Relationships between neurotrophic factors and transplant host integration. In: BJORKLUND, STENEVI (eds) Neural Grafting in Mammalian CNS. Elsevier, Amsterdam, pp. 169-178.

Cotman CW, Nieto-SAmpedro M 1985 Progress in facilitating the recovery of function after central nervous system injury. Hope for a New Neurology. Annals of the New York Academy of Science 457: 83-104.

DAs GD 1983 Neural transplantation in the spinal cord of adult rats. Conditions, survival, cytology and connectivity of the transplants. Fournal of the Neurological Sciences 62:191-210.

DimitriJevic MR 1988 Residual motor functions in spinal cord injury. In: WaxMan GS (ed) Advances in neurology, vol 47, Functional Recovery in Neurological Disease, Raven Press, New York.

Fallon JH, Seroogy KB, Loughlin SE, et al. 1984 Epidermal growth factor immunoreactive material in the central nervous system: location and development. Science 224:1107-1109.

FAWCETT JW, ROKOS J, BAKST I 1987 Axons regenerating in vitro avoid oligodendrocytes. Neuroscience Letters S2:53.

FOERSTER AP 1982 Spontaneous regeneration of cut axons in adult rat brain. Fournal of Comparative Neurology 210:335-356.

Gallon JH, Seroogy KB, Loughlin SE, et al. 1984 Epidermal growth factor immunoreactive material in the central nervous system: location and development. Science 224:1107-1109.

Guha A, TATOR CH, PIPER I 1987 Effect of calcium channel blocker on posttraumatic spinal cord blood flow. Fournal of Neurosurgery 66:423-430.

HALl ED, BRAUGHLER JM 1982 Glucocorticoid mechanisms in acute spinal cord injury: a review and therapeutic rationale. Surgical Neurology 18:320-327.

HAynes LW, SMITh ME, SMYTh DG 1984 Evidence for the neurotrophic regulation of collagen-tailed acetylcholinesterase in immature skeletal muscle by beta-endorphin. fournal of Neurochemistry 42:1542-1551.

Higgins AC, Pearlstein RD, Mullen JB, et al. 1981 Effects of hyperbaric oxygen therapy on long-tract neuronal conduction in the acute phase of spinal cord injury. Fournal of Neurosurgery 55:501-510.

JONES RF, UNSWORTH IP 1978 Hyperbaric oxygen and acute spinal cord injuries in humans. Medical fournal of Australia 2:573-575.

KaKulas BA 1987 The clinical neuropathology of spinal cord injury. A guide to the future. Paraplegia 25:212-216.

KAKUlAS BA, BEDBROOK GM 1969 A correlative clinico-pathological study of spinal cord injury. Proceedings of the Australian Association of Neurologists 6:123-132.

Kakulas BA, BedBrook GM 1976 Pathology of injuries of the vertebral column with emphasis on the macroscopical aspects. In: VINKEN PJ, BRUYN GW (eds) Handbook of Clinical Neurology, Vol 25. North Holland Publishing Co, Amsterdam, pp. 27-42.

KAO CC 1974 Comparison of healing process in transected spinal cords grafted with autogenous brain tissue, sciatic nerve and nodose ganglion. Experimental Neurology 44:424-439.

KLIGMAN D, MARSCHAK DR 1985 Purification and characterization of a neurite extension factor from bovine brain. Proceedings of the National Academy of Science 82:7136-7139.

LENN NJ 1987 Plasticity and responses of the immature nervous system to injury. Seminars in Perinatology 11(2):117-131.

Levi-Montalcini R 1968 Nerve growth factor. Physiology Review 48:534-569.

Levi-Montalcini R, Aloe L, Mugnaini E, et al. 1975 Nerve growth factor induces volume increase and enhances tyrosine hydroxylase synthesis in chemically axotomized sympathetic ganglia of newborn rats. Proceedings of the National Academy of Science, USA, 72:595-599.

LOGAN A, BerRy M, ThOMAS GH 1985 Identification and partial purification of fibroblast growth factor from the brains of developing rats and leucodystrophic mutant mice. Neuroscience 15(4):1239-1246.

Lund RD, Perry JHM Lagenaur CF 1986 Cell surface changes in the developing optic nerve of mice. Fournal of Comparative Neurology 247:439-446.

Marinesco G, Minea J 1906 Recherches sur la Regenerescence de la moelle. Nouvelle inconographie de la Salpetriere 19:417-440.

Midha R, Fehlings MG, Tator CH, et al. 1987 Assessment of spinal cord injury by counting corticospinal and rubrospinal neurons. Brain Research 410:299-308. 
Nieto-SAMPEDRo M, Cotman CW 1985 Growth factor induction and temporal order in CNS repair. In: Cotman CW (ed) Synaptic Plasticity, Guildford Press, New York, pp. 407-455.

Nieto-SAmpedro M, SANeto RP, Devellis J, et al. 1985 The control of glial populations in brain changes in astrocyte mitogenic and morphogenic factors in response to injury. Brain Research 343:320-328.

Nietro-SAmpedro M, Whittemore SR, NeEdels DL, et al. 1984 The survival of brain transplants is enhanced by extracts from injured brain. Proceedings of the National Academy of Science 81:6250-6254.

NoBle M, FoK-SEANG J, COHEN J 1984 Glia are a unique substrate for the in vitro growth of central nervous system neurons. Fournal of Neuroscience 4:1892-1903.

Perez-Polo RJ (ed) 1987 Neuronal Factors. CRC Press Inc, Florida.

RAIGORODSKY G, URCA G 1987 Intrathecal N-methyl-D-aspartate (NMDA) activates both nociceptive and antinociceptive systems. Brain Research 422:158.

RAISMAN G, EBNER FF 1985 Hippocampal transplants demonstrate the ability of the adult brain to receive and produce mossy fiber connections. In: ECCLES Sir J, DimitriJEvic MR (eds) Recent Achievements in Restorative Neurology. 1 Upper Motor Neuron Functions and Dysfunctions. Karger, Basel, pp 280-290.

RAISMAN G 1987 Genes aid spine patients. In: BANYARD P (ed) International Spinal Research Trust Newsletter No 12, pp. 4-5.

REIER PJ 1985 Annotation. Neural tissue grafts and repair of the injured spinal cord. Neuropathology and Applied Neurobiology 11:81-104.

Sotelo C, Alvarado-Mallart RM 1987 Reconstruction of the defective cerebellar circuitry in adult Purkinje cell degeneration mutant mice by Purkinje cell replacement through transplantation of solid embryonic implants. Neuroscience 20:1-22.

WALLACE MC, TATOR CH 1986a Failure of blood transfusion or naloxone to improve clinical recovery after experimental spinal cord injury. Neurosurgery 19(4):489-494.

WALLACE MC, TATOR CH 1986b Failure of naloxone to improve spinal cord blood flow and cardiac output after spinal cord injury. Neurosurgery 18(4):428-43.

Wallace MC, Tator CH, Piper I 1987 Recovery of spinal cord function induced by direct current stimulation of the injured rat spinal cord. Neurosurgery 20:878-988.

Whittemore SR, Nieto-SAMPedro M, NeEdels DL, et al. 1985 Neuronotrophic factors for mammalian brain neurons: injury induction in neonatal, adult and aged rat brain. Developmental Brain Research 20:169-178.

YEO JD 1976 A review of experimental research in spinal cord injury. Paraplegia 14:1-11.

YouNG W 1984 Pulsed electromagnetic fields alter calcium in spinal cord injury. The First International Symposium on Central Nervous System Trauma, Restoration, Plasticity, Regeneration. Fournal of the American Paralysis Association 1(1).

YounG W, FlAMM ES 1982 Effect of high-dose corticosteroid therapy on blood flow, evoked potentials, and extracellular calcium in experimental spinal injury. Fournal of Neurosurgery 57:667-673.

Young W, Flamm ES, Demopoulos HB, et al. 1981 Effect of naloxone on post-traumatic ischemia in experimental spinal contusion. Fournal of Neurosurgery 55:209-219.

Young W, YeN V, BLIGHT AR 1982 Extracellular calcium ionic activity in experimental spinal cord contusion. Brain Research 253:1-5-113. 